\title{
Plains gerbils Tatera robusta as prey of golden jackals and owls in the Serengeti National Park
}

\author{
Ramadhani B. M. SENZOTA
}

Senzota R. B. M. 1990. Plains gerbils Tatera robusta as prey of golden jackals and owls in the Serengeti National Park. Acta theriol. 35: 157-161.

Golden jackals Canis aureus Linnaeus, 1758 were found to prey on plains gerbils Tatera robusta (Cretszchmar, 1826) which were caught in live traps. The gerbils were the major prey of owls on the eastern Serengeti plains.

Wildlife Ecology Programme, Department of Zoology, University of Dar es Salaam, P.O. Box 35064, Dar es Salaam, Tanzania

Key words: predation, Tatera robusta, Tanzania

\section{Introduction}

There are no quantitative published data on the role of rodents as prey in the Serengeti National Park, Tanzania. The grass rat Arvicanthis niloticus has been reported to be part of the diet of black-backed jackals Canis mesomelas, serval cats Leptailurus serval, and barn owls Tyto alba (Laurie 1971, Geertsema 1976, 1985, Moehlman 1979, 1987). This paper reports observations on plains gerbils Tatera robusta (Cretszchmar, 1826) as prey of barn owls, spotted eagle owls Bubo africanus (Temminck, 1821) and golden jackals Canis aureus Linnaeus, 1758 in the Serengeti National Park.

Although barn and spotted eagle owls are widespread throughout tropical Africa (Burton 1973) knowledge of their ecology is very scanty. Even in such a well studied area as the Serengeti there is todate very little information on basic ecological aspects such as habitat and food habits of these owls. Burton (1973) stated that the owls eat small animals such as rodents, lizards, and snakes. The amounts of each food type eaten may differ between geographical zones and between seasons depending on availability of preferred food items.

There is much less information on golden jackals, which inhabit the open grassland regions of the Serengeti National Park, than there is on the black-backed jackals which occur in the woodland regions and whose ecology and behaviour have been appreciably studied by Moehlman $(1979,1987)$. Aspects of the ecology of the golden jackals would be particularly useful in that the jackals have been the second most numerous predators on the Serengeti Plains (Serengeti Research Institute 1977). Furthermore knowledge on the food habits of the owls and jackals in the Serengeti National Park would add into the accuracy on assessments of carrying capacity of the park, particularly the short grassland region which has been identified as the zone of highest grazing intensity by the migratory ungulates (Watson and Kerfoot 1964). 


\section{Materials and methods}

The study was conducted on the eastern short grassland plains of Serengeti National Park. During 1976 through 1978 live trapping was conducted on the short grassland plains (Senzota 1983, 1984). Serengeti traps (Senzota 1980) were set just before sunset and visited every two hours throughout the night to check for caught gerbils. For details of the study design see Senzota (1984). Torch-light was used during the visits. Golden jackals were observed to visit and open traps and prey on the caught gerbils. During the visits the number of golden jackals which were flashed by the torch-light was recorded. Records were also nade of traps which were opened by the jackals and of traps which caught gerbils, but which were not opened by the jackals. Traps opened by jackals had scratch marks on them and usually fur remains and blood stains from the extracted gerbils were left in the traps.

During 1977 through 1979, owl pellets were collected from four owl nest sites. The four collection sites were at Ngarenanyuki (six times), Gol kopjes (six times), Barafu kopjes (seven times) and Naabi hill (once). Each pellet was subsequently examined for the remains of plains gerbils, other vertebrates and insects Statistical treatments followed Siegal and Castellan (1988).

\section{Results and discussion}

During the wet season trapping sessions (February and March), no jackals were flashed with torch-light on the area where traps were set (Table 1). During the other sessions jackals were seen in the area. Of the traps which had caught gerbils, proportionately more were opened by jackals during the dry season sessions (August,

Table 1. Number of jackals flashed with torch-light, traps opened by jackals, and traps which caught gerbils but which were not opened by the jackals. Short grassland plains, Serengeti National Park, Tanzania.

\begin{tabular}{lccc}
\hline Session & Flashed jackals & $\begin{array}{c}\text { Traps opened } \\
\text { by jackals }\end{array}$ & $\begin{array}{c}\text { Traps not opened } \\
\text { by jackals }\end{array}$ \\
\hline October' 76 & 9 & 6 & 2 \\
March '77 & 0 & 0 & 21 \\
June '77 777 & 4 & 5 & 1 \\
August '77 & 1 & 1 & 4 \\
October' 77 & 3 & 10 & 1 \\
December '77 & 0 & 6 & 6 \\
February '78 & 0 & 1 & 9 \\
\hline
\end{tabular}

October and December) than during the wet season sessions (January, February and March) $\left(23 / 36\right.$ and $6 / 37$ respectively; $\chi^{2}=5.832, p<0.02$, Table 1). Thete was a positive, but not significant, correlation between the number of jackals which were flashed by torch-light and the number of traps which were opened by jackals $\left(r_{\mathrm{s}}=0.536\right.$, $0.10<p<0.25$ ). There was a significant negative correlation between the number of jackals flashed on the study area and the number of traps which caught gerbils bit were not opened by the jackals $\left(r_{\mathrm{s}}=0.759, p<0.05\right.$, Table 1$)$.

The jackals may have converged on the study area and opened the traps beacause of the scarcity of prey elsewhere. Fawns of Thomson's gazelles Gazella thomsoni are a favourite food item of golden jackals, so the jackals concentrated their feecing on 
gazelle fawns during the wet season, which was the peak calving period for the gazelles. Wyman (1967) observed that during the major calving season (January - April) Thomson's gazelles constituted $50 \%$ of the food of golden jackals on the eastern Serengeti plains.

According to the predictions of Pulliam (1974) on optimal foraging theory, jackals would be expected to increase their preying on the gerbils as the relative abundance of the gerbils increased, but only if gerbils were a preferred prey. Since the relative abundance of the gerbils on the study area did not show significant variation between seasons (Senzota 1984) and since golden jackals there quit preying on the gerbils during the wet season when their other prey increased in number, it can be suggested that gerbils were a low quality prey of the golden jackals. This finding contrasts with that on black-backed jackals, which are of similar body size as the golden jackals, but which feed heavily on grass rats Arvicanthis niloticus. The body size of grass rats is of similar magnitude to that of the plains gerbils.

During the dry seasons gazelles moved into the woodlands and the dung-beetles, which were another major prey for the jackals, were observed to aestivate underground. With valuable prey items missing the diet may be expanded to include gerbils. Thus gerbils may nevertheless be a major food source (albeit of low quality) for the jackals during the dry season. Faecal analysis or field studies of jackal hunting are needed. In numbers, golden jackals were the second most numerous predator on the Serengeti plains during the dry season (Serengeti Research Institute 1977).

Of the vertebrate, the plains gerbils

Table 2. Percentages of owl pellets which contained skulls of Tatera robusta for the period between February 1977 and February 1978 at the three sites in the Serengeti National Park, Tanzania.

\begin{tabular}{lccc}
\hline \multirow{2}{*}{ Aspect } & \multicolumn{3}{c}{ Site } \\
\cline { 2 - 4 } & Ngarenanyuki & Gol & Barafu \\
\hline Mean & 74.4 & 79.2 & 81.9 \\
SE & 5.4 & 12.0 & 5.1 \\
$\%$ SE/mean & 7.2 & 15.1 & 6.3 \\
\hline
\end{tabular}

were the major prey of the owls. For any one visit the maximum number of owls seen nesting were three barn owls, one each at Barafu and Gol kopjes and Naabi hill and two spotted eagle owls at Ngarenanyuki kopjes. Assuming that the gerbil made up more than $90 \%$ of the ingested items which constituted a pellet containing the skull of a gerbil, it can be inferred from Table 2 that the gerbils contributed over $70 \%$ of the food of the owls. Pairing the months of December and February 1978, June, August and October 1977, for Ngarenanyuki with the respective months for Gol and Barafu, the Ngarenanyuki site had significantly (sign test, $p<0.05, n=5$ ) more pellets than either Gol or Barafu (Table 3). The cumulative number of pellets containing Tatera robusta skulls were 743 for Ngarenanyuki, 122 for Gol and 128 for Barafu (Table 3). Collections at Gol and Barafu kopjes were lower and tended to vary from session to session.

Using $85.2 \mathrm{~g}$ as the average weight for the gerbils (Senzota 1983) the owls which roosted and nested at Ngarenanyuki consumed 41 gerbils per month for the collections of June 1977 through February 1978; this was equivalent to 175.2 prey units of ger- 
Table 3. Prey remains in pellets of owls at Serengeti National Park, Tanzania. $W=$ wet season, $D=d r y$ season.

\begin{tabular}{|c|c|c|c|c|c|}
\hline $\begin{array}{l}\text { Month } \\
\text { of collection }\end{array}$ & $\begin{array}{c}\text { Pellets with } \\
\text { Tatera skulls }\end{array}$ & $\begin{array}{l}\text { Pellets with skulls } \\
\text { of other vertebrates }\end{array}$ & $\begin{array}{l}\text { Pellets with } \\
\text { insect remains }\end{array}$ & $\begin{array}{l}\text { Pellets with } \\
\text { no skulls }\end{array}$ & $\begin{array}{l}\text { Total No. of } \\
\text { pellets collected }\end{array}$ \\
\hline \multicolumn{6}{|c|}{ Ngarenanyuki } \\
\hline Feb. '77 W & 384 & 3 & 2 & 54 & 441 \\
\hline June '77 W & 109 & 6 & 15 & 24 & 139 \\
\hline Aug. $77 \mathrm{D}$ & 89 & 19 & 1 & 37 & 145 \\
\hline Oct. 77 D & 72 & 10 & 0 & 34 & 116 \\
\hline Feb. '78 W & 59 & 5 & 2 & 7 & 71 \\
\hline Dec. '78 W & 30 & 22 & 57 & 5 & 57 \\
\hline \multicolumn{6}{|c|}{ Gol } \\
\hline June ' $77 \mathrm{~W}$ & 84 & 0 & 15 & 6 & 90 \\
\hline Aug. ' $77 \mathrm{D}$ & 4 & 0 & 0 & 0 & 4 \\
\hline Oct. 77 D & 1 & 0 & 0 & 0 & 4 \\
\hline Dec. $77 \mathrm{~W}$ & 11 & 2 & 5 & 1 & 14 \\
\hline Feb. '78 W & 10 & 0 & 3 & 1 & 11 \\
\hline Dec. 78 D & 12 & 0 & 13 & 1 & 13 \\
\hline \multicolumn{6}{|c|}{ Barafu } \\
\hline March $77 \mathrm{~W}$ & 30 & 0 & 3 & 2 & 32 \\
\hline June ' $77 \mathrm{~W}$ & 30 & 0 & 5 & 8 & 38 \\
\hline Aug. '77 D & 4 & 0 & 0 & 0 & 4 \\
\hline Oct. $77 \mathrm{D}$ & 17 & 1 & 0 & 5 & 23 \\
\hline Dec. ${ }^{7} 77 \mathrm{~W}$ & & 0 & 5 & 1 & 3 \\
\hline Feb. '78 W & 28 & 1 & 0 & 7 & 36 \\
\hline Dec. '78 W & 17 & 1 & 17 & 0 & 18 \\
\hline \multicolumn{6}{|c|}{ Naabi } \\
\hline May '79 W & 5 & 56 & 64 & 2 & 64 \\
\hline
\end{tabular}

bils per month (sensu Southern 1954). The total for the eight months was 1381.6 prey units. The lowest two-monthly figures was 4.25 prey units obtained for the one skull collected in October 1977 at Gol kopjes. The highest was 379.1 prey units obtained at the Ngarenanyuki site in August 1977.

In Britain, Southern (1954) noted a high monthly variation (range 42.0-1033.2 units in 1947) of rodent prey units eaten by Tawny owls because of changes in vegetation cover. When cover was low owls were able to capture more rodents. In the Serengeti, Laurie (1971) found a cumulative number of only 24 skulls (equivalent to 74.4 prey units) of Arvicanthis at Oloserian kopjes (a wooded long grassland habitat) and 145 skulls (equivalent to 449.7 prey units) at Masai kopjes (a more open habitat), despite the very high abundance of Arvicanthis at Oloserian (Laurie 1971, Senzota 1982). On the short grassland plains where my study was conducted the grass was short (less than $10 \mathrm{~cm}$ ); seasonal variation in prey unit may have been caused by seasonal variation in the number of owls at the sites. Southern (1954) noted considerable variation of number of owls at some of his collection sites; similar studies are needed for the Serengeti plains. The abundance of the Serengeti plains gerbils did not show significant seasonal variation (Senzota 1984); at Barafu kopjes a number of decapitated unconsumed gerbils were always present in the nest, suggesting that as prey the gerbils were abundant. 
Acknowledgements: I thank E. Palangyo, J. Masse, T. Maleko and F. Sichalwe for field assistance. Dr. J. Rood introduced me to rodent morphometrics as a tool for identification. Financial support was provided by the Serengeti Wildlife Research Institute and the African Wildlife Fundation. I thank Dr. Flowerdew for his valuable comments and Mrs. Leonard for typing the manuscript.

\section{References}

Burton J. A. 1973. Owls of the world: their evolution, structure and ecology. Smeets, Offset, Wert, Neatherland. - Geertsema A. A. 1976. Impressions and observations on serval behaviour in Tanzania, East Africa. Mammalia 40:13-19. - Geertsema A. A. 1985. Aspects of the ecology of the serval Leptailurus serval in the Ngorongoro Crator, Tanzania. Neth. J. Zool. 35: 527-610. - Laurie W. A. 1971. The food of the barn owl on the Serengeti National Park, Tanzania. J. E. Afr. Nat. Hist. Soc. Mus. 28: 1-4. - Moehlman P. D. 1979. Jackal helpers and pup survival. Nature 277: 382-383.

Moehlman P. D. 1987. Social organization in jackals. Am. Scient. 75: 366-375. - Pulliam H. R. 1974. On the theory of optimal diets. Am. Nat. 108: 59-74 _ - Senzota R. B. M. 1980. The Serengeti trap. Trop. Pest Manage. 26:385-390. - Senzota R. B. M. 1982. The habitat and food habits of grass rats (Arvicanthis niloticus) in the Serengeti National Park, Tanzania. Afr. J. Ecol. 20: 241-252. Senzota R. B. M. 1983. The plains gerbil. Mammalia 47: 583-585. - Senzota R. B. M. 1984. The habitat, abundance and burrowing habits of the gerbil, Tatera robusta, in the Serengeti National Park, Tanzania. Mammalia 48: 185-195. - Serengeti Research Institute, 1977. Census of predators and other animals on the Serengeti plains. Serengeti National Park Report No. 73. - Siegel S. and Castellan N. J. 1988. Non parametric statistics for the behavioural sciences. McGraw Hill Book. Co., New York. - Southern H. N. 1954. Tawny owls and their prey. Ibis 96: 384-410. - Watson R. M. and Kerfoot O. 1964. A short note on the intensity of grazing of the Serengeti Plains by plains game. Z. Säugetierk. 29: 317-320. - Wyman J. 1967. The jackals of the Serengeti. Animals 10: 79-83.

Received 17 May 1989, accepted 4 February 1990. 